\title{
Poly(ether ester)s from Pivalolactone, Alkanediols, and Dimethyl Terephthalate. 1. Synthesis, Structure Analysis, and Reaction Mechanism
}

\author{
E. J. Tijsma, ' L. van der Does, and A. Bantjes \\ Department of Chemical Technology, University of Twente, P.O. Box 217, \\ 7500 AE Enschede, The Netherlands
}

\author{
N. K. de Vries, I. Vulić, and G. H. Werumeus Buning \\ DSM Research, P.O. Box 18,6160 MD Geleen, The Netherlands
}

Received March 2, 1993; Revised Manuscript Received June 11, 1993

\begin{abstract}
The reaction of mixtures of pivalolactone (PVL), alkanediols, and dimethyl terephthalate (DMT) was investigated in a two-stage melt process. NMR measurements $\left({ }^{1} \mathrm{H},{ }^{13} \mathrm{C},{ }^{1} \mathrm{H}-{ }^{1} \mathrm{H},{ }^{1} \mathrm{H}-{ }^{13} \mathrm{C}\right)$ indicated that poly(ether ester)s had been formed. Apart from a significant amount of ether bonds, the copolymers contained practically no PVL sequences, which was also observed using a model system consisting of bis(hydroxybutyl) terephthalate and PVL. From the results of the model study it was concluded that ring opening of PVL had occurred by attack on the $\beta$-carbon atom, followed by alkyl-oxygen bond scission, thus leading to the formation of ether bonds. Furthermore, it was found that propagation through successive attacks on PVL had not taken place; instead the formed carboxylic acid end groups reacted with hydroxyl groups, resulting in isolated PVL units in the polymeric chains. In this paper also data are presented about the effect of the catalyst and of the type of lactone on the copolymer synthesis.
\end{abstract}

\section{Introduction}

Several methods have been employed for the synthesis of polyesters, including direct esterification, interchange reactions, reaction of acid chlorides with hydroxyl groups, and ring-opening polymerization of cyclic esters. These methods have also been used for the preparation of polyester (block) copolymers. The synthesis of copolyesters using both condensation and ring-opening reactions is dealt with in numerous patents, but generally these different reaction types are applied in subsequent experiments only. Thus, polyester block copolymers have been prepared by treating preformed polyesters, e.g., poly(ethylene terephthalate) (PET), with lactones, especially $\epsilon$-caprolactone. ${ }^{1-5}$ Recently, Luo et al. described the synthesis and (thermal) properties of a series of $\epsilon$-caprolactone/ethylene terephthalate block copolymers. 6,7 The structure of these segmented copolymers ${ }^{8}$ and of $\epsilon$-caprolactone/butylene terephthalate block copolymers ${ }^{9}$ was elucidated using NMR spectroscopy.

Only a few studies are known which report the preparation of copolyesters by condensation and ring-opening polymerization simultaneously. Random copolymers have been synthesized from mixtures of terephthalic acid, aliphatic glycols, and lactones. ${ }^{10,11}$ Recently, the structure and properties of random copolyesters prepared by reaction of mixtures of 1,4-butanediol, terephthalic acid, and $\epsilon$-caprolactone have been determined in order to investigate the composition-properties relationship. ${ }^{12}$

As part of our study on the synthesis of copolymers containing the pivalolactone (PVL) unit, introduction of other groups in polypivalolactone (PPVL) by means of interchange reactions was investigated. ${ }^{13,14}$ We obtained random copolymers with a high thermal stability after heating of PPVL with Bisphenol A polycarbonate and dimethyl terephthalate (DMT). ${ }^{14}$

As mentioned above, random copolymers can also be prepared by applying condensation and ring-opening reactions simultaneously. Starting with PVL, we studied the synthesis of copolyesters and investigated the structure and reaction mechanism. (The properties of the copolymers will be discussed in a forthcoming paper. ${ }^{15}$ )
In this paper, results are presented of processes carried out in the molten state for the synthesis of copolymers from PVL, alkanediols, and DMT, i.e., with $\mathrm{R}=\mathrm{CH}_{3}$ and $\mathrm{R}^{\prime}=\left(\mathrm{CH}_{2}\right)_{n}$ (Scheme I). In these syntheses $x$ mol of PVL, $y \mathrm{~mol}$ of DMT, and $2 y \mathrm{~mol}$ of alkanediol were reacted in the melt in the presence of tetrabutylorthotitanate as a catalyst. Ester interchange between DMT and alkanediols was assumed to occur in the first stage, followed by ring opening of PVL. In order to study the formation of copolymers in more detail, a model system was used in which reactions of bis(hydroxybutyl) terephthalate with PVL were investigated. Results are also presented on the effect of the type of lactone on the reactions with alkanediols and DMT in the melt. For the characterization of the copolymers, NMR spectroscopy, DSC, and viscometric measurements were used.

\section{Experimental Section}

Materials. Pivalolactone was purified by distillation over calcium hydride and was stored under nitrogen at $-30^{\circ} \mathrm{C}$. $\epsilon$-Caprolactone $(\epsilon \mathrm{C})$, dimethyl terephthalate, 1,3-propanediol (D3), and 1,4-butanediol (D4) were obtained from Merck and were used as received. The other lactones used were purchased from Aldrich and were used without further purification. Tetrabutylorthotitanate (TnBT; Merck) and stannous octoate (SnOct; Sigma) used as catalysts in the polymerization procedures were added as solutions in dry toluene. Bis(hydroxybutyl) terephthalate (BHBT), mp $72^{\circ} \mathrm{C}$, was synthesized from DMT and a 20 -fold excess of D4.16 The structure of this compound was confirmed by ${ }^{1} \mathrm{H}$ NMR spectroscopy.

Trifluoroacetic acid (Janssen Chimica) and chloroform (Merck) were used without further purification. The ethanol used for precipitation was of technical grade. The chloroform used in the viscometric measurements and titrations was purified by standard procedures. Acetic anhydride, 1,2-dichloroethane (both from Merck), and $N$-methylimidazole (Aldrich) were used as received.

Synthesis of Copolymers. Polymerizations were carried out by a two-stage process in a 30 (or 50 )-mL reaction vessel, equipped with a stainless steel stirrer and an inlet for nitrogen. A condenser with a provision for applying a vacuum was attached through a sidearm. The glass reactor was heated using a temperaturecontrolled $\left( \pm 2{ }^{\circ} \mathrm{C}\right.$ ) salt bath (10 parts of potassium nitrate and 8.5 parts of sodium nitrate). 
Scheme I. Possible Route for the Synthesis of Copolymers from PVL

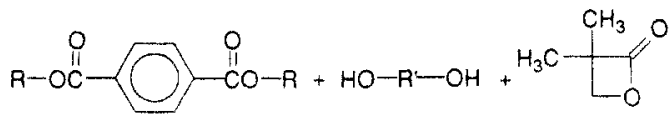

$$
-\mathrm{ROH}
$$

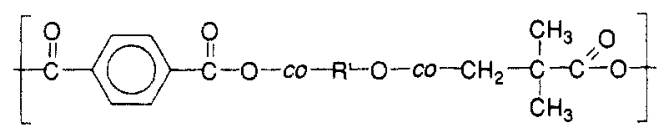

Table I. Characteristics of Copolymers Synthesized from

\begin{tabular}{|c|c|c|c|c|c|c|c|c|}
\hline \multirow[b]{3}{*}{ exp. no. } & \multicolumn{6}{|c|}{ composition (mol \%) } & \multirow{3}{*}{$\begin{array}{c}\eta_{\mathrm{inh}^{\alpha}} \\
(\mathrm{dL} / \mathrm{g})\end{array}$} & \multirow{3}{*}{$\begin{array}{l}T_{\mathrm{m}}^{b} \\
\left({ }^{\circ} \mathrm{C}\right)\end{array}$} \\
\hline & \multicolumn{3}{|c|}{ initial } & \multicolumn{3}{|c|}{ finale } & & \\
\hline & $\overline{\text { PVL }}$ & $D n^{d}$ & $\overline{\mathrm{DMT}}$ & $\overline{\text { PVL }}$ & $D n^{d}$ & $\overline{\mathrm{DMT}}$ & & \\
\hline $\begin{array}{l}\text { D-50/01 } \\
\text { D-60/01 } \\
\text { D-70/01 } \\
\text { D-80/01 } \\
\text { D-90/01 }\end{array}$ & $\begin{array}{l}8 \\
4\end{array}$ & $\begin{array}{l}38 \\
44 \\
50 \\
55 \\
58 \\
62 \\
64\end{array}$ & $\begin{array}{l}2 y \\
31 \\
32\end{array}$ & $\begin{array}{l}8 \\
4\end{array}$ & $\begin{array}{l}46 \\
47 \\
47 \\
52 \\
49 \\
51 \\
52\end{array}$ & 44 & $\begin{array}{l}\text { ns } \\
\text { ns } \\
\text { ns }\end{array}$ & $\begin{array}{l}\text { liq } \\
87 \\
125 \\
160 \\
177 \\
201 \\
203\end{array}$ \\
\hline $\begin{array}{l}\text { 4D-30/01 } \\
\text { 4D-40/01 } \\
\text { 4D-50/01 } \\
\text { 4D-60/01 } \\
\text { 4D-70/01 } \\
\text { 4D-80/01 } \\
\text { 4D-90/01 } \\
\text { 4D-100/01 }\end{array}$ & $\begin{array}{r}44 \\
33 \\
25 \\
18 \\
13 \\
8 \\
4 \\
0\end{array}$ & $\begin{array}{l}38 \\
44 \\
50 \\
55 \\
58 \\
62 \\
64 \\
66\end{array}$ & $\begin{array}{l}19 \\
22 \\
25 \\
27 \\
29 \\
31 \\
32 \\
33\end{array}$ & $\begin{array}{r}13 \\
8 \\
3 \\
0\end{array}$ & $\begin{array}{l}41 \\
44 \\
47 \\
49 \\
51 \\
52 \\
49 \\
50\end{array}$ & $\begin{array}{l}24 \\
28 \\
32 \\
36 \\
41 \\
48 \\
50\end{array}$ & $\begin{array}{l}0.08 \\
0.13 \\
0.29 \\
0.40 \\
0.46 \\
\text { ns } \\
\text { ns } \\
\text { ns }\end{array}$ & $\begin{array}{l}\text { liq } \\
\text { liq } \\
117 \\
143 \\
177 \\
200 \\
210 \\
218\end{array}$ \\
\hline $\begin{array}{l}\text { D3D-60/01 } \\
\text { D3D-60/02 } \\
\text { D3D-60/03 }\end{array}$ & $\begin{array}{l}18 \\
18 \\
18\end{array}$ & $\begin{array}{l}55 \\
55 \\
55\end{array}$ & $\begin{array}{l}27 \\
27 \\
27\end{array}$ & $\begin{array}{l}18 \\
22 \\
19\end{array}$ & $\begin{array}{l}52 \\
49 \\
49\end{array}$ & $\begin{array}{l}31 \\
30 \\
31\end{array}$ & $\begin{array}{l}0.32 \\
0.08 \\
0.18\end{array}$ & $\begin{array}{l}160 \\
130 \\
158\end{array}$ \\
\hline
\end{tabular}
PVL, Alkanediols, and DMT with TnBT as a Catalyst ( $3 \mathrm{~h}$, $\left.200-250{ }^{\circ} \mathrm{C}, \mathrm{N}_{2} ; 2 \mathrm{~h}, 250^{\circ} \mathrm{C}, 0.1 \mathrm{mbar}\right)$

a Determined in chloroform at $25^{\circ} \mathrm{C}(c=0.50 \mathrm{~g} / \mathrm{dL}) ; \mathrm{ns}=$ not soluble in chloroform. ${ }^{b}$ Determined from second heating curve; liq $=$ viscous liquid at $25^{\circ} \mathrm{C} .{ }^{\circ}$ Determined from ${ }^{1} \mathrm{H}$ NMR spectra in deuterated chloroform or trifluoroacetic acid. ${ }^{d}$ D3 $=1,3$-propanediol D4 = 1,4-butanediol. ${ }^{e}$ Without catalyst. $f$ With SnOct as a catalyst.

In a typical polymerization procedure, $\mathrm{PVL}(4.00 \mathrm{~g}, 40.0 \mathrm{mmol})$ DMT (11.64 g, 60.0 mmol), D4 $(10.80 \mathrm{~g}, 120.0 \mathrm{mmol})$, and TnBT $(0.1$ wt \%) were placed in the reaction vessel (Table I, exp. no. PD4D-60/01). The reaction vessel was evacuated and flushed with nitrogen three times and inserted into the salt bath kept at $200^{\circ} \mathrm{C}$. Within 5 min a clear melt was formed, and while the contents were stirred under nitrogen for $2 \mathrm{~h}$, the methanol formed was distilled out. The temperature was raised to $250^{\circ} \mathrm{C}$ over a period of $30 \mathrm{~min}$ and was kept at $250^{\circ} \mathrm{C}$ for another $30 \mathrm{~min}$. During these $3 \mathrm{~h}, 3.26 \mathrm{~g}$ of distillate, i.e., $85 \%$ of the theoretical amount of methanol, was collected. In the second stage of the reaction a vacuum $(20 \mathrm{mmHg})$ was applied for $30 \mathrm{~min}$ and the polymerization was completed by heating at $250^{\circ} \mathrm{C}$ and $0.1 \mathrm{mbar}$ for $2 \mathrm{~h}$. The clear viscous melt was cooled to room temperature, during which the melt solidified and a white polymer was formed. After purification by dissolving in $30 \mathrm{~mL}$ of chloroform, followed by precipitation in $1000 \mathrm{~mL}$ of ethanol, $16.72 \mathrm{~g}$ of a white fiberforming polymer with $\eta_{\text {inh }}=0.40 \mathrm{dL} / \mathrm{g}$ in chloroform was obtained.

Model System. Mixtures of PVL $(1.00 \mathrm{~g}, 10.0 \mathrm{mmol})$, BHBT $(3.10 \mathrm{~g}, 10.0 \mathrm{mmol})$, and TnBT $(0.1$ wt \%) were placed in $10-\mathrm{mL}$ polymerization tubes equipped with a provision for either applying a vacuum or keeping a nitrogen atmosphere. After evacuating and flushing with nitrogen three times, the tubes were inserted into the salt (or oil) bath kept at the desired temperature. After different reaction times, the tubes were removed from the temperature-controlled bath, quenched, dissolved in hot toluene, cooled to room temperature, and filtered. Because of the experimental setup used, the maximum conversion of PVL was $80 \%$, due to condensation of PVL on the upper, not thermostated, part of the tubes.
Reaction products (prepolymers) were analyzed by ${ }^{1} \mathrm{H}$ NMR spectroscopy and by end-group determinations via titration.

Hydroxyl End Group Determination. The number of hydroxyl end groups was determined using an acetylation procedure described by Dee et al. ${ }^{17}$ In a typical procedure, prepolymer $(0.2-0.3 \mathrm{~g})$ was dissolved in $10 \mathrm{~mL}$ of purified chloroform. Excess acetic anhydride was added from a diluted solution ( $1 / 6$ by volume) of acetic anhydride in 1,2-dichloroethane. After addition of $1 \mathrm{~mL}$ of $N$-methylimidazole, the flask was purged with nitrogen and placed in a $100^{\circ} \mathrm{C}$ bath for $15 \mathrm{~min}$. After cooling to room temperature, $1.5 \mathrm{~mL}$ of water was added to hydrolyze the unreacted acetic anhydride at $100^{\circ} \mathrm{C}$ for $5 \mathrm{~min}$. The solution was cooled and titrated with methanolic $\mathrm{KOH}$ to a thymol blue endpoint.

Carboxylic Acid End Group Determination. The amount of carboxylic acid end groups was measured by dissolving prepolymer $(0.3-0.5 \mathrm{~g})$ in $20 \mathrm{~mL}$ of pyridine, followed by potentiometric titration with tetrabutylammonium hydroxide in 2-propanol. Most of the products showed one equivalence point; only when the reaction was carried out at $200^{\circ} \mathrm{C}$ did the reaction products obtained after $60 \mathrm{~min}$ of reaction and longer show a second equivalence point.

Measurements. Viscometric measurements were carried out with solutions of $0.050 \mathrm{~g}$ of polymer in $10 \mathrm{~mL}$ of chloroform, using an Ubbelohde viscometer thermostated at $25^{\circ} \mathrm{C}$. NMR spectra were recorded on a Bruker AC 250F or on a Varian Unity 300 using a deuterated solvent; chemical shifts are in parts per million downfield from TMS. For the H,H-COSY spectra 16 scans were performed for 512 experiments, covering a sweep width of $3000 \mathrm{~Hz}$. For the H,C-COSY experiments 192 scans were collected for every $t_{1}$ value. A $1 \mathrm{~K} \times 128 \mathrm{~K}$ data set was acquired to cover a sweep of $10000 \mathrm{~Hz}$ in the $F_{2}$ dimension and $3000 \mathrm{~Hz}$ in the $F_{1}$ dimension. Data were processed using sinebell windows in both dimensions. Thermal analyses were carried out at a heating/cooling rate of $20^{\circ} \mathrm{C} / \mathrm{min}$ using a Perkin-Elmer DSC 7 . For calibration gallium and indium were used; all DSC runs were carried out under a nitrogen atmosphere.

\section{Results and Discussion}

Copolymer Synthesis from Pivalolactone, Alkanediols, and Dimethyl Terephthalate. Polymers were synthesized by simultaneous condensation and ringopening polymerization of PVL, alkanediols, and DMT. During the first stage of the reactions between PVL, alkanediols, and DMT, almost quantitative amounts of methanol were formed, indicating the occurrence of ester interchange as the initial step (Scheme I). Moreover, it appeared that, from the reactions of bis(hydroxybutyl) terephthalate (BHBT) and PVL, copolymers were obtained with the same structure as formed from PVL, 1,4butanediol (D4), and DMT, thus indicating that reactions with PVL only occurred after ester interchange between the alkanediols and DMT.

At the end of the interchange reactions, the initiation step of PVL polymerization involving ring opening took place. In spite of the relatively low boiling point of PVL, i.e., $110^{\circ} \mathrm{C}$, no significant loss of lactone was observed. In the second stage, the polymerization was completed under vacuum after the temperature had been increased to 250 ${ }^{\circ} \mathrm{C}$.

The characteristics of polymers synthesized by this twostage process from PVL, DMT, and 1,3-propanediol (D3) and D4 are presented in Table I. Most of the polymers were soluble in chloroform, in which neither polypivalolactone (PPVL) nor the corresponding poly(alkylene terephthalate)s are soluble. These results suggest that during the two-stage melt process copolymers had been formed. The composition of the copolymers, listed in Table I, was calculated from ${ }^{1} \mathrm{H}$ NMR data. The ${ }^{1} \mathrm{H}$ NMR spectrum of PD4D-50/01 (see Table I) is presented in Figure 1, along with the spectra of PPVL, poly(butylene terephthalate) (PBT), and a blend of both homopolymers. 
(A)

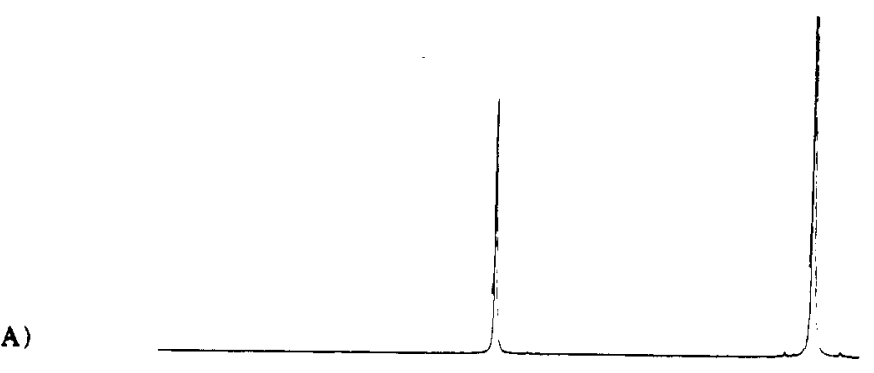

(B)

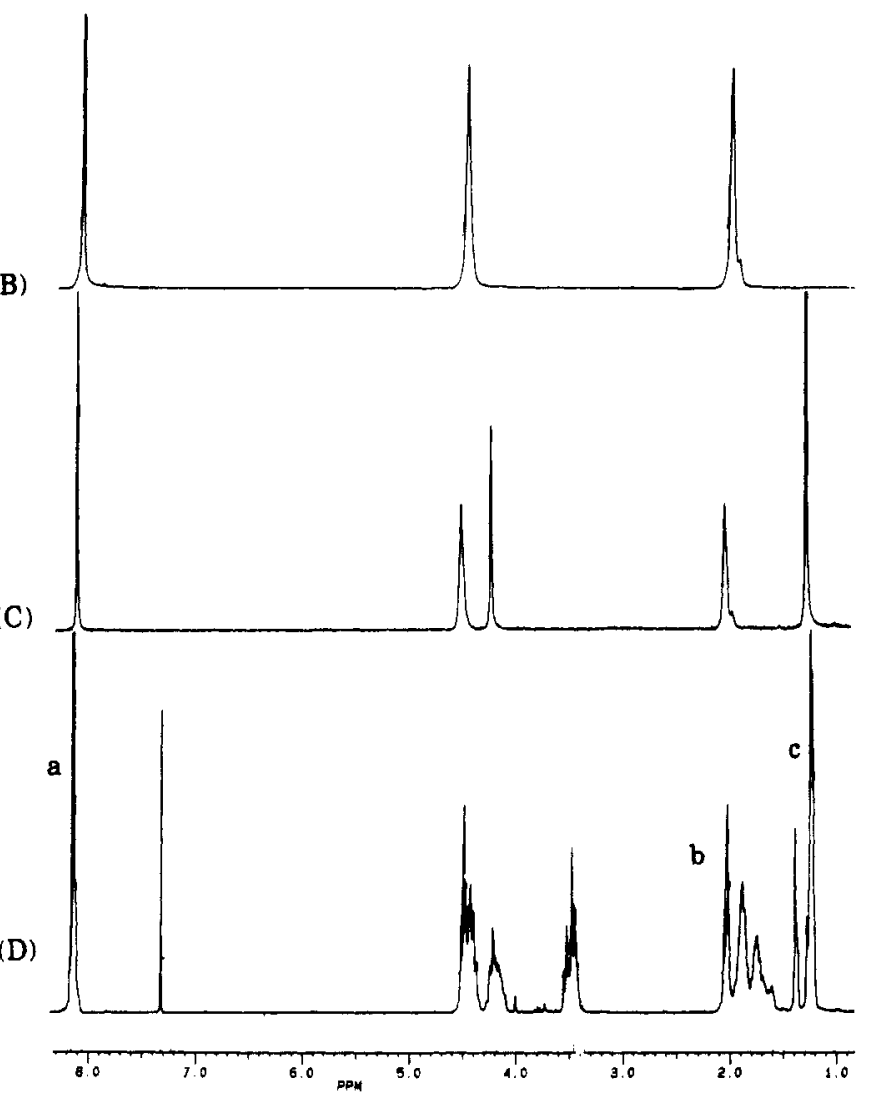

Figure 1. 'H NMR spectra of PPVL (A), PBT (B), a blend (C), and a copolymer prepared from PVL, D4, and DMT (D) (exp. no. PD4D-50/01; see Table I).

Using the peaks a-c (shown in Figure 1), the composition of the copolymers with D4 could be calculated. Peak a was assigned to the aromatic protons of the terephthalate unit and peak $b$ to the four center methylene protons of the butylene unit, while peak c corresponded with the methyl protons of the PVL unit. In a similar way the compositions of the other copolymers, listed in Table I, were determined.

From the compositional data it can be seen that in the copolymers the Dn/DMT ratio was larger than 1 and that this ratio decreased with decreasing amounts of PVL in the copolymers. The fact that the $\mathrm{D} n / \mathrm{DMT}$ ratio is not equal to 1 is remarkable, for in the synthesis of poly(alkylene terephthalate)s always a Dn/DMT ratio of 1 is found. Table I also gives viscometric data and data about some thermal properties of the copolymers. These results as well as the effect of the composition of the copolymers on the properties will be discussed in more detail in a forthcoming paper. ${ }^{15}$

The influence of the catalyst on the synthesis of the copolymers from PVL, alkanediols, and DMT was also studied (see Table I). In one run (exp. no. PD3D-60/02) no catalyst was added, whereas in another experiment (exp. no. PD3D-60/03) 0.1 wt \% stannous octoate (SnOct) was used as a catalyst. Without catalyst, both weight recovery $(17 \%)$ and $\eta_{\text {inh }}$ of the resulting polymer were very

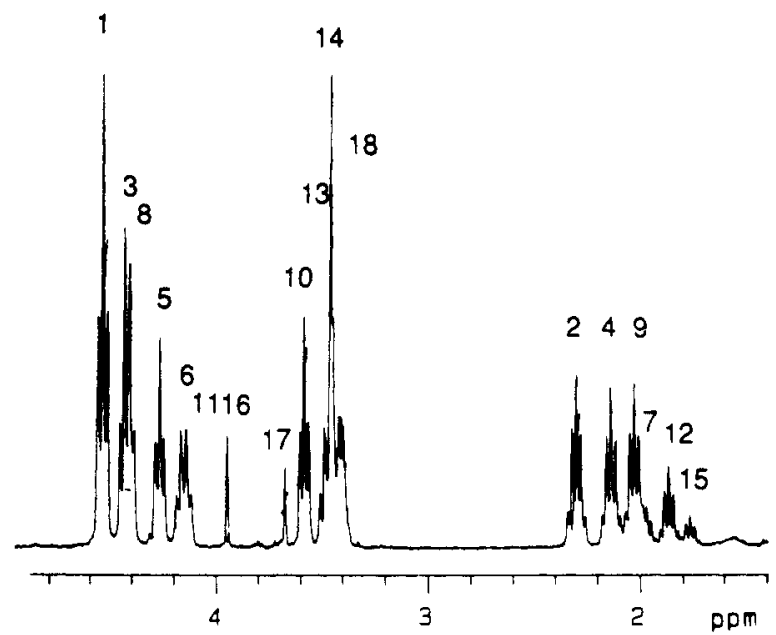

Figure 2. Aliphatic region between 1.5 and $4.8 \mathrm{ppm}$ of the ${ }^{1} \mathrm{H}$ NMR spectrum of a copolymer prepared from PVL, D3, and DMT (exp. no. PD3D-50/01; see Table I).

low, and the ${ }^{1} \mathrm{H}$ NMR spectrum showed a large peak at $\delta=3.95 \mathrm{ppm}$ corresponding with methyl terephthalate end groups. By using SnOct, known for its catalytic activity in the alcohol-initiated polymerization of lactones, ${ }^{18}$ the weight recovery of polymer was considerably higher $(67 \%)$. However, the value of $\eta_{\text {inh }}$ remained low, especially as compared with the $\eta_{\text {inh }}$ of the polymer obtained in the experiment in which TnBT was used as a catalyst (exp. no. PD3D-60/01).

Microstructure of the Copolymers Studied by NMR. As shown in Figure 1, not only was a broadening of the peaks in the ${ }^{1} \mathrm{H}$ NMR spectrum of the copolymer observed, but also peaks were present between $\delta=3.3$ and $3.6 \mathrm{ppm}$, indicating the presence of ether bonds in the copolymer. These peaks were found in the spectra of all copolymers prepared from PVL, alkanediols, and DMT. In order to elucidate the origin of these ether structures, a more detailed NMR study was carried out $\left({ }^{1} \mathrm{H},{ }^{13} \mathrm{C},{ }^{1} \mathrm{H}-\right.$ ${ }^{1} \mathrm{H},{ }^{1} \mathrm{H}-{ }^{13} \mathrm{C}$ ). The copolymers prepared from PVL, D3, and DMT were studied in particular, for the NMR spectra of these copolymers showed the highest resolution. A detailed assignment was not possible in the case of the copolymers from D4, due to peak overlap.

The aliphatic region of the ${ }^{1} \mathrm{H}$ NMR spectrum of copolymer PD3D-50/01 (see Table I) between 1.5 and 4.8 ppm is presented in Figure 2. Apart from the characteristic peaks coming from the aromatic protons of the terephthalate unit at $\delta=8.1 \mathrm{ppm}$ and from the protons of the methyl groups of the PVL unit at $\delta=1.2 \mathrm{ppm}$ (both not shown in Figure 2), the ${ }^{1} \mathrm{H}$ NMR spectrum showed peaks corresponding with the central methylene protons of the propylene unit centered at $\delta=2.0 \mathrm{ppm}$. Finally, the resonances between $\delta=3.3$ and $4.6 \mathrm{ppm}$ arose from the $\mathrm{CH}_{2} \mathrm{O}$ protons of both the propylene and the PVL unit.

The six resonances near $\delta=2.0 \mathrm{ppm}$ resulted from the nature of both adjacent units. Six possible structures are presented in Scheme II, i.e., three symmetrical (A, C, and F) and three asymmetrical structures (B, D, and E). Starting from the central protons of the propylene unit, the structures could be distinguished by means of homonuclear $(\mathrm{H}, \mathrm{H})$-correlated NMR spectroscopy (COSY), for only one cross peak occurred in the case of the symmetrical structures, whereas two cross peaks were present for the asymmetrical ones. Figure 3 shows the COSY spectrum of copolymer PD3D-50/01, i.e., the region between $\delta=1.5$ and $4.8 \mathrm{ppm}$. In the COSY spectrum nine cross peaks were found in accordance with the six structures presented in Scheme II. The signal at $\delta=2.30 \mathrm{ppm}$, which gave one 
Scheme II. Possible Triad Sequences of Copolymers Prepared from PVL, D3, and DMT with the Propylene Unit as the Center Unit

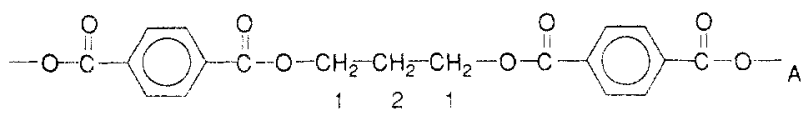

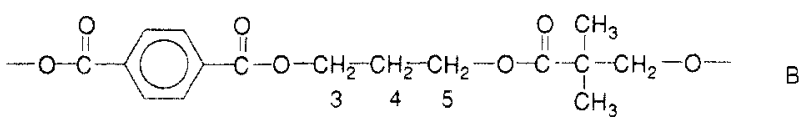

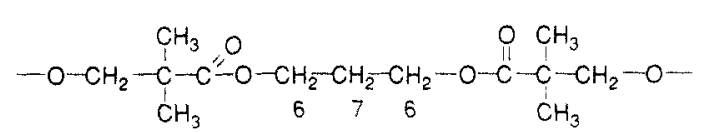

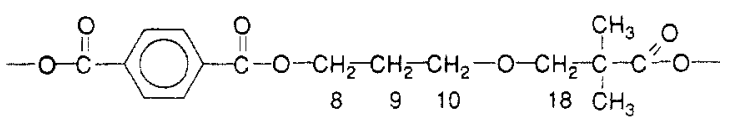

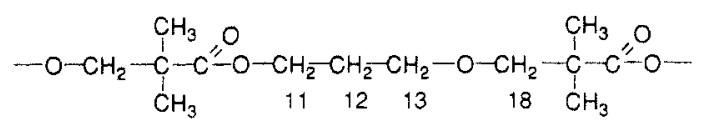

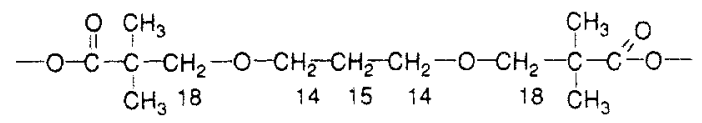

cross peak at $\delta=4.53 \mathrm{ppm}$, was assigned to the symmetrical structure with terephthalate units (A, Scheme II), for it is known that $\mathrm{CH}_{2} \mathrm{O}$ protons next to a terephthalate unit have a resonance at lower field than those next to a PVL unit. The peak at $\delta=2.13 \mathrm{ppm}$ appeared to have two cross peaks, i.e., with resonances at $\delta=4.42$ and $4.26 \mathrm{ppm}$. Being characteristic for $\mathrm{CH}_{2} \mathrm{OCO}$ protons, these peaks corresponded to structure B. Since the protons at $\delta=$ 2.01 and $1.85 \mathrm{ppm}$ were coupled to both protons in the region of ether resonances (between $\delta=3.3$ and $3.6 \mathrm{ppm}$ ) and to protons next to ester groups $(\delta=4.40$ and 4.12 ppm, respectively), only structures $D$ and $E$ were possible.
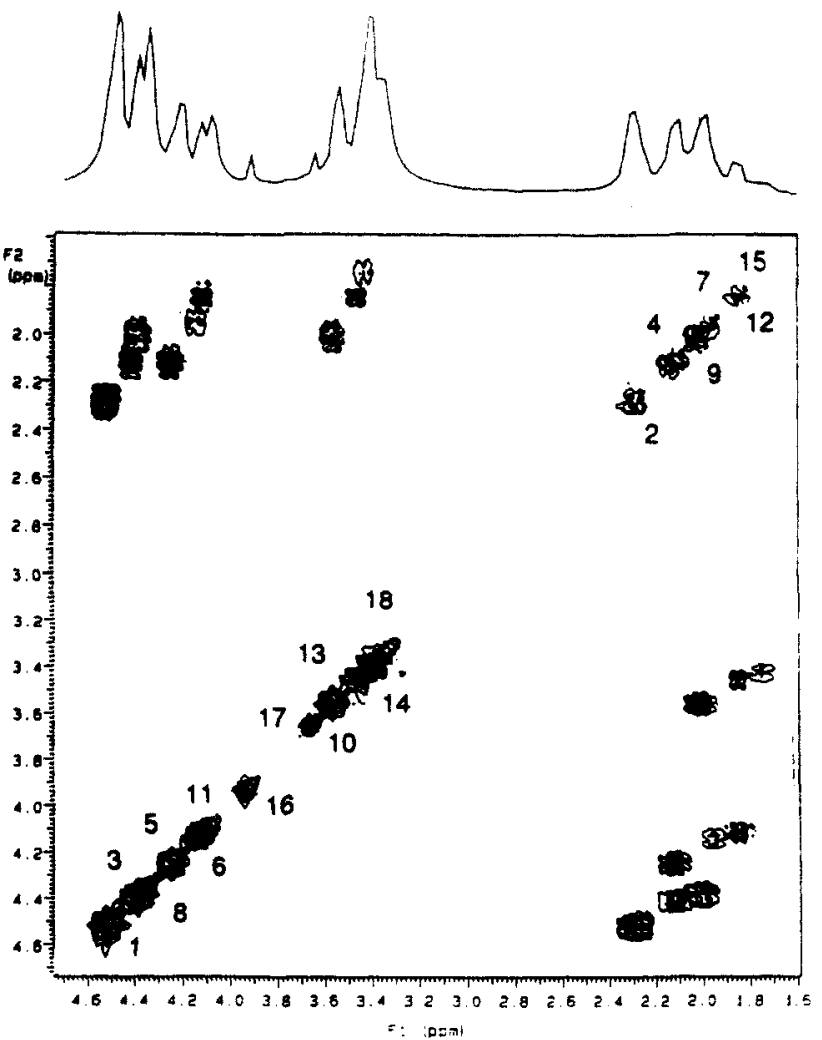

Figure 3. (H,H)-COSY spectrum of a copolymer prepared from PVL, D3, and DMT (exp. no. PD3D-50/01; see Table I).
Table II. Chemical Shifts in the ${ }^{1} \mathrm{H}$ and ${ }^{12} \mathrm{C}$ NMR Spectra of a Copolymer Prepared from PVL, D3, and DMT (exp. no. PD3D-50/01; See Table I)

\begin{tabular}{lcccc}
\hline & & & \multicolumn{2}{c}{${ }^{13} \mathrm{C}$ shift $(\mathrm{ppm})$} \\
\cline { 4 - 5 } structure & atom & ${ }^{1}$ H shift (ppm) & exptl & calcd $^{a}$ \\
\hline A & 1 & 4.53 & 62.0 & 62.1 \\
& 2 & 2.30 & 28.2 & 29.5 \\
B & 3 & 4.42 & 62.6 & 62.1 \\
& 4 & 2.13 & 28.2 & 29.5 \\
& 5 & 4.26 & 60.8 & 63.1 \\
C & 6 & 4.15 & 61.6 & 63.1 \\
& 7 & 1.97 & 28.2 & 29.5 \\
D & 8 & 4.40 & 61.9 & 62.2 \\
& 9 & 2.01 & 29.0 & 30.6 \\
& 10 & 3.57 & 67.9 & 66.7 \\
E & 11 & 4.12 & 60.8 & 63.2 \\
& 12 & 1.85 & 29.0 & 30.6 \\
& 13 & 3.47 & 68.4 & 66.7 \\
F & 14 & 3.43 & 67.9 & 66.8 \\
& 15 & 1.74 & 29.8 & 32.2 \\
G & 16 & 3.95 & 69.8 & 72.3 \\
H & 17 & 3.67 & 70.6 & 73.3 \\
D, E, F & 18 & 3.45 & 77.6 & \\
& & & &
\end{tabular}

${ }^{a}$ Accuracy 2 ppm.

Scheme III. Esters of PVL in Copolymers Prepared from PVL, D3, and DMT

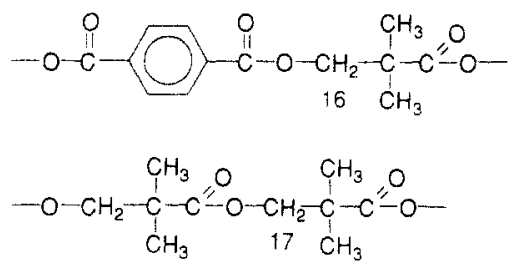

For above-mentioned reasons, i.e., protons next to a terephthalate unit give peaks at lower field, the peak at $\delta=2.01$ ppm was assigned to structure D. Consequently, structure $\mathrm{E}$ corresponded to the peaks at $\delta=1.85,3.47$, and $4.12 \mathrm{ppm}$. The signal at $\delta=1.97 \mathrm{ppm}$ gave one cross peak at $\delta=4.15 \mathrm{ppm}$. The latter is characteristic for $\mathrm{CH}_{2-}$ OCO protons next to a PVL unit, and therefore these peaks were assigned to structure C. Finally, the signal at $\delta=$ $1.74 \mathrm{ppm}$, showing one cross peak at $\delta=3.43 \mathrm{ppm}$, came from structure $\mathrm{F}$. The results of the complete analysis of the spectrum between $\delta=1.5$ and $4.8 \mathrm{ppm}$ are given in Table II.

The singlets at $\delta=3.95$ and $3.67 \mathrm{ppm}$ were assigned to the methylene protons of the PVL unit next to a terephthalate unit and next to a PVL unit, respectively (structures G and H, Scheme III), whereas the broad peak at $\delta=3.45 \mathrm{ppm}$ corresponded with the methylene protons of the PVL unit next to ether bonds (structures D-F, scheme II).

Figure 4 shows (part of) the $(\mathrm{H}, \mathrm{C})$-COSY spectrum of a copolymer prepared from PVL, D3, and DMT. Since the chemical shifts of the protons were known, the corresponding ${ }^{13} \mathrm{C}$ shifts could be found. In Table II these values are tabulated together with the values calculated using chemical shift rules and the proposed structures of Schemes II and III. ${ }^{19}$ From Table II it can be seen that both experimental and calculated values are in good agreement. Three groups of ${ }^{13} \mathrm{C}$ resonances could be distinguished for the central carbon atom of the propylene unit: at $\delta=28.2 \mathrm{ppm}$ corresponding with completely esterified structures $(\mathrm{A}-\mathrm{C})$, at $\delta=29.8 \mathrm{ppm}$ assigned to the two-sided etherified structure $(F)$, and at $\delta=29.0 \mathrm{ppm}$ corresponding with the mixed structures (D and E). Apart from the fact that the calculated values followed the same trend $(\delta=29.5,32.2$, and $30.6 \mathrm{ppm})$, it should be noticed 


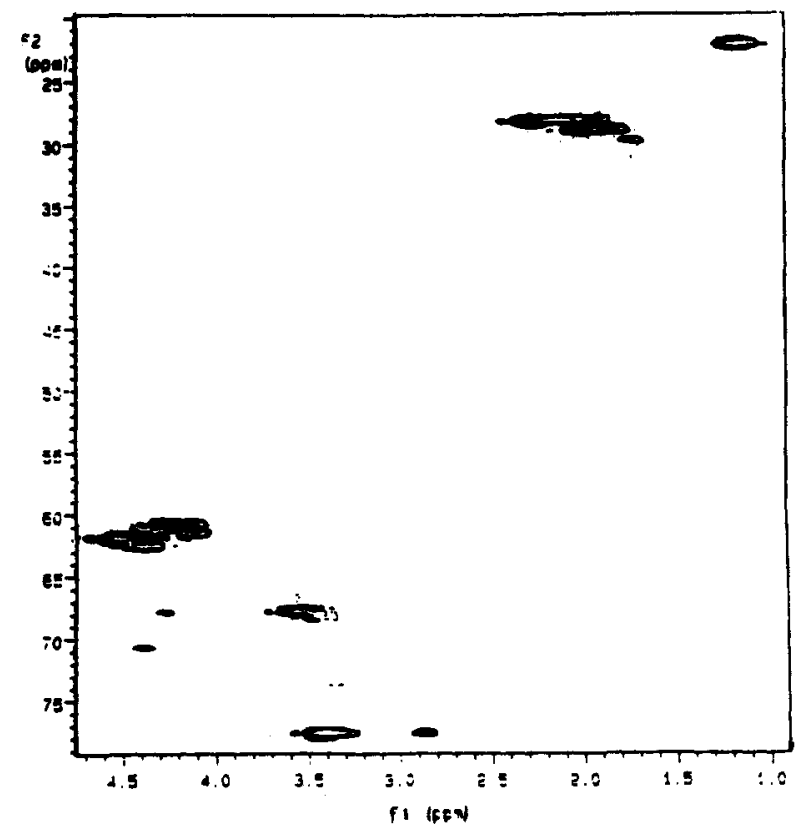

Figure 4. (H,C)-COSY spectrum of a copolymer prepared from PVL, D3, and DM'T (exp. no. PD3D-50/01; see Table I).

Table III. Microstructure of Copolymers Prepared from PVL, D3, and DMT (See Also Table I)

\begin{tabular}{ccccccccc}
\hline & \multicolumn{7}{c}{ structure } \\
\cline { 2 - 9 } exp. no. & A & B & C & D & E & F & G & H \\
\hline PD3D-30/01 & 18 & 20 & 13 & 17 & 17 & 10 & 2 & 3 \\
PD3D-40/01 & 21 & 24 & 11 & 20 & 13 & 6 & 1 & 4 \\
PD3D-50/01 & 25 & 24 & 7 & 24 & 11 & 6 & 1 & 2 \\
PD3D-60/01 & 41 & 23 & 3 & 24 & 10 & 0 & 0 & 0 \\
PD3D-70/01 & 61 & 17 & 2 & 19 & 1 & 0 & 0 & 0 \\
PD3D-80/01 & 72 & 13 & 0 & 15 & 0 & 0 & 0 & 0 \\
PD3D-90/01 & 83 & 10 & 0 & 7 & 0 & 0 & 0 & 0 \\
PD3D-60/01 & 41 & 23 & 3 & 24 & 10 & 0 & 0 & 0 \\
PD3D-60/02 & 31 & 20 & 5 & 27 & 8 & 0 & 0 & 8 \\
PD3D-60/03 & 44 & 22 & 2 & 21 & 8 & 0 & 0 & 3
\end{tabular}

a Structures as presented in Schemes II and III.

that the absolute values lay within the accuracy ( $\pm 2 \mathrm{ppm}$ ) of the predicted chemical shifts.

It could also be concluded from the ${ }^{13} \mathrm{C}$ NMR spectrum that neither nonreacted D3 (calculated resonance for the central methylene protons is $\delta=36.1 \mathrm{ppm}$ ) nor one-sided reacted D3 (calculated resonance is $\delta=33.5 \mathrm{ppm}$ ) was present in copolymer PD3D-50/01. Also the presence of other compounds such as D3 ethers could be excluded. By checking the integrals of the ether resonances in the ${ }^{1} \mathrm{H}$ NMR spectrum, it was confirmed that no other ether structures were present. Besides, the calculated integral for the aromatic structures (A, B, D, and G) corresponded to the integral of the terephthalate protons. Therefore, it was assumed that the copolymers prepared from PVL, D3, and DMT can be completely described by the structure A-H shown in Schemes II and III.

Using the assignments as presented above, the microstructure of several copolymers of the PD3D series was determined at triad level. From the results presented in Table III for copolymers with different compositions, it can be seen that the predominant structures present in the copolymers prepared are A, B, and D. Furthermore, the amount of structures containing ether bonds, i.e., $D-F$, was considerable (up to $44 \mathrm{~mol} \mathrm{\%}$ ) and decreased to $7 \mathrm{~mol}$ $\%$ with decreasing number of PVL units in the copolymers. It should also be noted that PVL was mainly present as isolated units in the polymer chains; i.e., the amount of PVL sequences (H; Scheme III) is almost negligible. Comparing microstructural data of copolymers prepared
Scheme IV. Anionic Ring Opening of Lactones with Acyl-Oxygen Bond Scission (a) or with Alkyl-Oxygen Bond Scission (b,c)
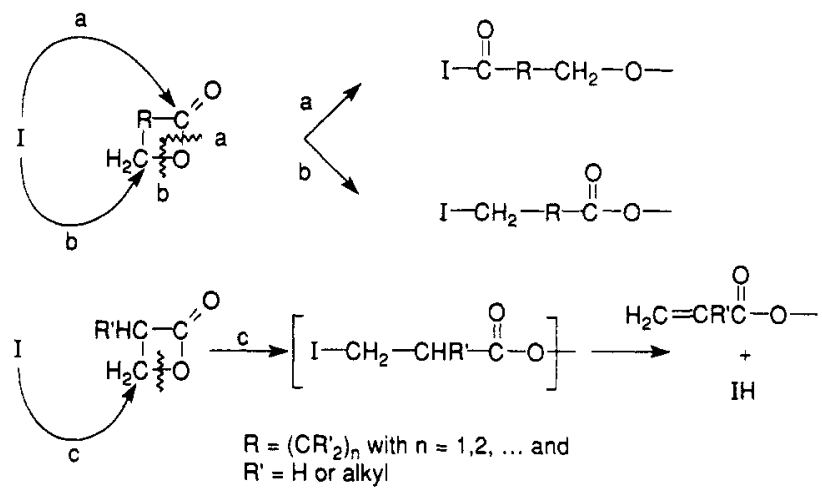

Scheme V. Hydrolytic Ring Opening with Acyl-Oxygen Bond Scission for $\delta$ - and $\epsilon$-Lactones (a) or with Alkyl-Oxygen Bond Scission for $\beta$-Lactones (b)
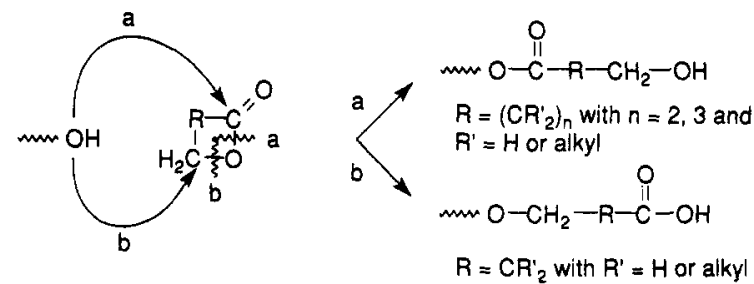

with different catalysts, it is also clear that the copolymer obtained using TnBT as a catalyst (exp. no. PD3D-60/01) contained no PVL sequences, whereas in the other polymers (exp. no. PD3D-60/02 and 03) several mol \% of these sequences were present.

Reactions Occurring during Synthesis of Poly(ether esters)s. In order to explain the results of the NMR study, in particular concerning the presence of ether bonds in the copolymers and the absence of PVL sequences, the ring-opening reaction of PVL was studied in more detail. Several types of ring-opening reactions by anionic initiators are known for lactones, in particular $\beta$-lactones. ${ }^{20}$ Two routes represent the classical initiation reactions for the formation of linear polyesters by ring opening of lactones. Ring opening with acyl-oxygen bond scission results in the formation of alcoholate end groups (a; Scheme IV), whereas ring opening with alkyl-oxygen bond scission leads to carboxylate end groups (b; Scheme IV). ${ }^{21,22}$ The nature of the initiation step of anionic lactone polymerization depends both on the ring size of the cyclic ester and on the initiator used. In the case of $\delta$ - and $\epsilon$-lactones the initiation step involves attack of the initiator on the carbonyl carbon atom followed by acyl-oxygen bond scission (a; Scheme IV). When hydroxyl groups are used for initiation, an $\omega$-hydroxy ester is formed ( $a$; Scheme V.) ${ }^{18,21,23,24}$

In the anionic polymerization of the highly strained and planar $\beta$-lactones, the attack on the carbonyl carbon atom is more difficult ${ }^{25}$ and the occurrence of both reactions (a and b; Scheme IV) was proposed. Yamashita et al. suggested acyl-oxygen bond scission when strong nucleophiles were used as initiators (a; Scheme IV). ${ }^{26}$ Several authors assumed the occurrence of both reactions in the initial stage of $\beta$-lactone polymerization. ${ }^{22,25}$ The occurrence of both types appeared to be inconsistent with results with alkali-metal alkoxides as initiator. ${ }^{27,28} \mathrm{Kurcok}$ et al. reinvestigated the mechanism of the anionic polymerization of $\beta$-lactones with alkoxides as initiators and a mechanism was proposed, in which simultaneously alkyloxygen and acyl-oxygen bond scission was excluded (c; Scheme IV). ${ }^{29,30}$ 


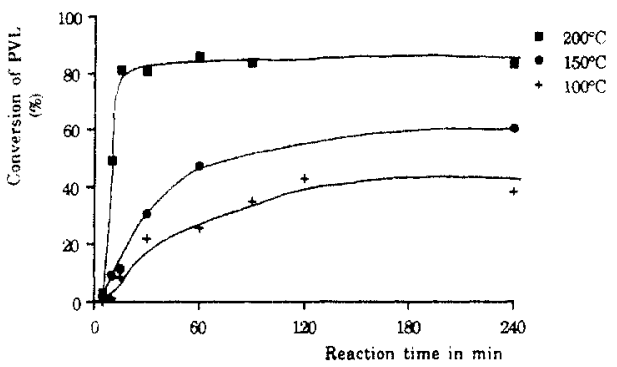

Figure 5. Ring opening of PVL by BHBT in the presence of TnBT at various reaction temperatures vs reaction time.

Recently, metal anions have been employed as initiators for $\beta$-lactone polymerization: the mechanism of polymerization with organic alkali-metal complexes was reported to involve carbon-carbon bond scission in the initiation step and both acyl- and alkyl-oxygen bond scission for the propagation. ${ }^{31}$ Weak nucleophiles are unable to give rise to acyl-oxygen bond scission, thus resulting in attack on the $\beta$-carbon atom followed by alkyl-oxygen bond scission (b; Scheme V). $22,32,33$

Apart from the studies carried out on the unsubstituted $\beta$-propiolactone, several reports are known concerning the nucleophile-initiated polymerization of $\alpha, \alpha$-disubstituted $\beta$-lactones. Hall proposed that the polymerization of these disubstituted $\beta$-lactones with carboxylate initiators occurred by an $\mathrm{S}_{\mathrm{N}} 2$ reaction at the $\mathrm{CH}_{2}$ group, followed by alkyl-oxygen bond scission (b; Scheme V). ${ }^{34}$ In several papers the nucleophile-initiated polymerization of $\alpha, \alpha$ dimethyl- $\beta$-propiolactone, i.e., PVL, via alkyl-oxygen bond scission has been proposed. . $^{34-37}$

Ring opening of PVL in the copolymer synthesis starting from PVL, alkanediols, and DMT was assumed to be initiated by bis(hydroxyalkyl) terephthalates, formed after ester interchange between DMT and the alkanediols. This assumption was based on data from the NMR spectra. It was concluded from the spectra of the copolymers prepared from PVL, D3, and DMT that PVL units were mainly present isolated in the polymer chains and linked to two propylene units (structures B and D; Scheme II), i.e.

$$
-\mathrm{OCH}_{2} \mathrm{CH}_{2} \mathrm{CH}_{2}-\mathrm{O}-\mathrm{CH}_{2}-\mathrm{CH}_{3}-\mathrm{C}-\mathrm{O}=-\mathrm{CH}_{2} \mathrm{CH}_{2} \mathrm{CH}_{2} \mathrm{O}-
$$

As mentioned before, copolymers with the same structure, i.e., with ether bonds and isolated PVL units, were formed after completion of the reaction when using PVL and bis(hydroxybutyl) terephthalate (BHBT) instead of PVL, D4, and DMT. Therefore, as a model system, the ring-opening polymerization of PVL was studied by reacting equimolar amounts of PVL and BHBT. At various reaction times samples were taken from the model system during the first stage of the process, i.e., before applying a vacuum. The samples were analyzed by ${ }^{1} \mathrm{H}$ NMR spectroscopy and by end-group determinations via titration.

In Figure 5 the effect of the reaction conditions on the ring opening of PVL by BHBT is shown. Reactions were studied at various temperatures, and it appeared that, already after $15 \mathrm{~min}$ at $200^{\circ} \mathrm{C}$ (i.e., temperature also used during the first stage of the copolymer synthesis), the conversion of PVL was complete, since due to the experimental setup only a maximum conversion of $80 \%$ could be obtained at $200^{\circ} \mathrm{C}$ (see the Experimental Section). In Figure 6 the number of end groups determined via titration is plotted as a function of the reaction time at different temperatures. The results of the hydroxyl end-
(A)

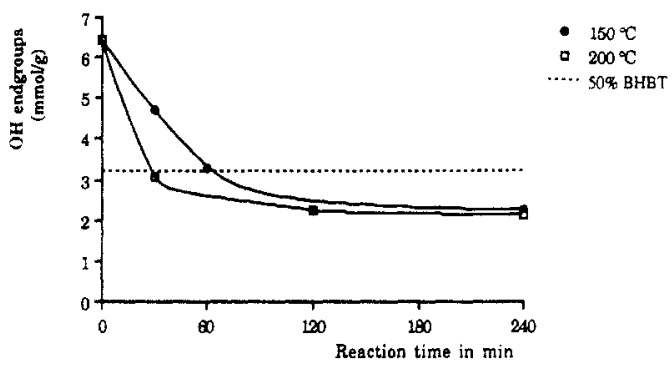

(B)

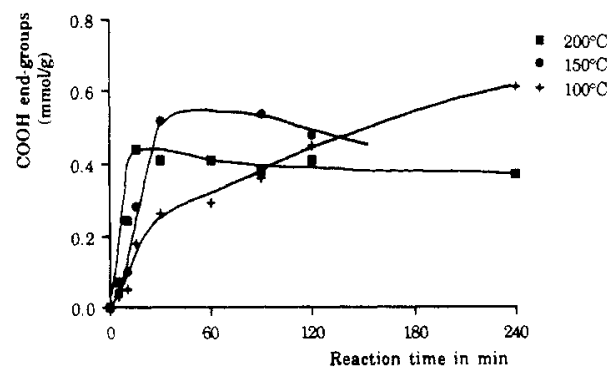

Figure 6. Number of hydroxyl (A) and carboxylic acid (B) end groups in the reaction of PVL with BHBT in the presence of TnBT at various reaction temperatures vs reaction time.

group determinations show a decrease for the number of hydroxyl end groups after $15 \mathrm{~min}$ (Figure 6A), whereas an increase for the amount of carboxylic acid end groups is observed (Figure 6B).

Initiation of the ring-opening polymerization of $\beta$-lactones by weak nucleophiles involves an attack on the $\beta$-carbon atom, followed by alkyl-oxygen scission ( $b$; Scheme V). ${ }^{22,32,33}$ Because BHBT can be considered as a weak nucleophile, the results presented in Figures 5 and 6 as well as the formation of ether bonds suggest the following reaction:

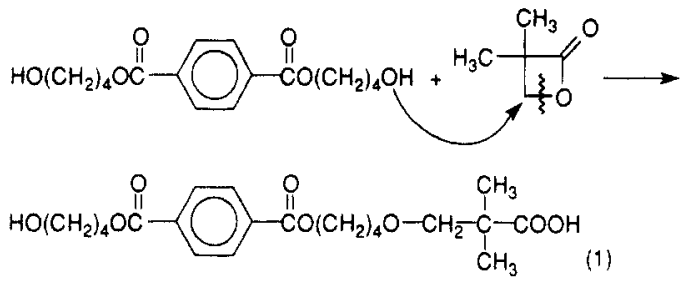

Next, polymerization might proceed by successive attacks of the formed carboxylic end groups on PVL, in analogy with data reported on the polymerization by carboxylate anions: ${ }^{34-38}$

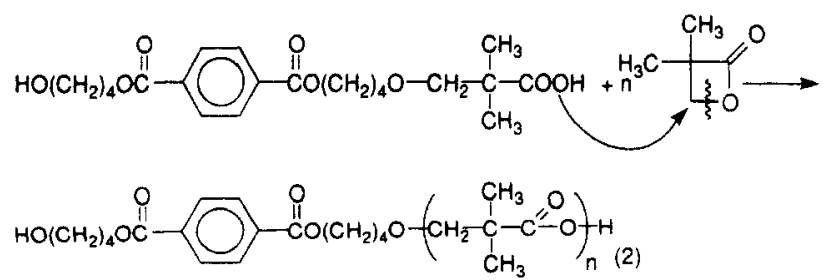

From Figure 6A it is obvious that the number of hydroxyl end groups dropped below the level of $50 \%$ of the initially present hydroxyl end groups. This large decrease could not be explained by the occurrence of reaction (1). Even in the most unfavorable case, i.e., when $1 \mathrm{~mol}$ of PVL reacts with $1 \mathrm{~mol}$ of BHBT, still $50 \%$ of the initially present hydroxyl end groups should remain present in the reaction products, for the initial mixture contained equimolar amounts of PVL and BHBT.

Figure 6B shows an initial increase of the number of carboxylic acid end groups at $200^{\circ} \mathrm{C}$ followed by a decrease. These results do not indicate the occurrence of reaction 
(2), for during the propagation reaction the number of carboxylic acid end groups should remain constant, i.e., only dependent on reaction (1). Moreover, the absence of PVL sequences in the reaction products was in disagreement with the occurrence of reaction (2).

Therefore, we propose that the decrease in the number of both types of end groups is caused by the reaction of the formed carboxylic acid end groups with the hydroxyl groups of BHBT:

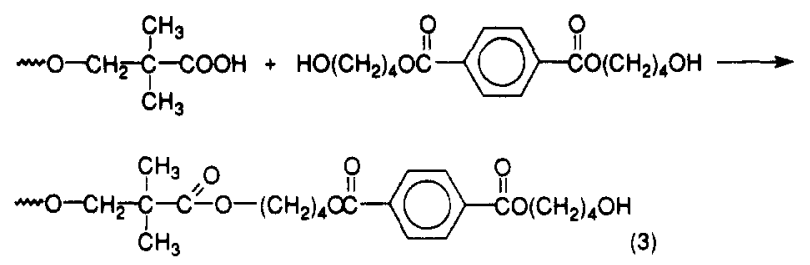

It must also be considered that condensation reactions between BHBT molecules take place, resulting in a decrease of the number of hydroxyl end groups. Furthermore, if carboxylic acid end groups are formed by reaction (1) without further reactions, a value of $2.1 \mathrm{mmol} / \mathrm{g}$ for the amount of these end groups should be obtained. The fact that this value was never reached together with the decrease in the number of carboxylic acid end groups observed for reaction times more than $15 \mathrm{~min}$ at $200^{\circ} \mathrm{C}$ might indicate the occurrence of reaction (3).

As shown before (see Table III), the copolymers prepared by the two-stage process consisted mainly of the structures A, B, and D (Scheme II) and contained hardly PVL sequences (H; Scheme III). These results are in agreement with the occurrence of reaction (3), which accounts for the formation of isolated PVL units present in the form of structures B and D.

From these results it can be concluded that initiation occurred readily and that propagation did not take place. Furthermore, it appeared that the ring opening of every PVL molecule required one hydroxyl group, resulting in one ether group per reacted PVL molecule. In contrast to the results obtained using TnBT as a catalyst, several mol \% of PVL sequences were found present in copolymers using no catalyst or SnOct as a catalyst (see Table III). This is in accordance with the fact that catalysis by SnOct of condensation reactions, such as reaction (3), has not been reported.

During the reaction of PVL with BHBT at $200^{\circ} \mathrm{C}$, another type of carboxylic acid end group was formed after $60 \mathrm{~min}$ of reaction and longer, possibly resulting from an interchange reaction as shown below:

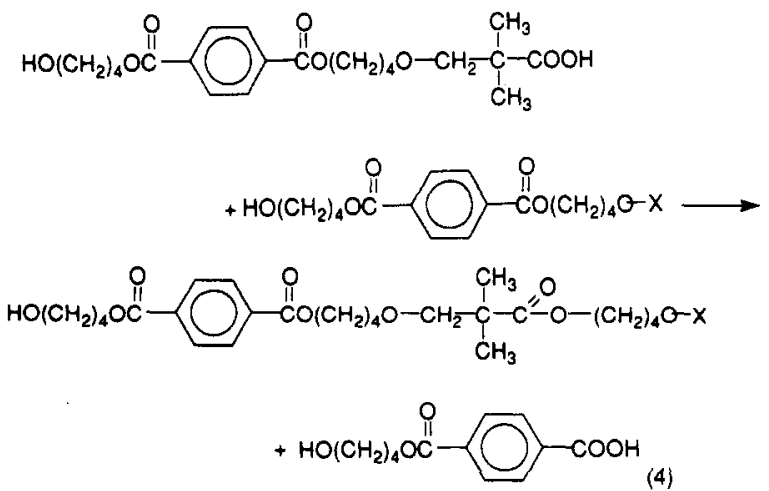

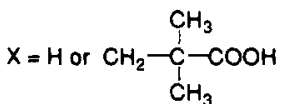

Table IV. Characteristics of Polymers Synthesized from Various Lactones, Alkanediols, and DMT

\begin{tabular}{|c|c|c|c|c|c|c|c|}
\hline \multirow[b]{3}{*}{ exp. no. } & \multicolumn{6}{|c|}{ composition (mol \%) } & \multirow{3}{*}{$\begin{array}{c}\text { ether } \\
\text { bonds } \\
(\%)\end{array}$} \\
\hline & \multicolumn{3}{|c|}{ initial } & \multicolumn{3}{|c|}{ final $^{b}$} & \\
\hline & lactone $e^{c}$ & $\overline{\mathrm{D} n^{d}}$ & $\overline{\mathrm{DMT}}$ & lactone $e^{c}$ & $\mathrm{D} n^{d}$ & $\overline{\mathrm{DMT}}$ & \\
\hline $\begin{array}{l}\text { PD3D-50/01 } \\
\text { PD3D-70/01 } \\
\text { PD4D-50/01 } \\
\text { PD4D-70/01 }\end{array}$ & $\begin{array}{l}25 \\
13 \\
25 \\
13\end{array}$ & $\begin{array}{l}50 \\
58 \\
50 \\
58\end{array}$ & $\begin{array}{l}25 \\
29 \\
25 \\
29\end{array}$ & $\begin{array}{l}25 \\
12 \\
25 \\
13\end{array}$ & $\begin{array}{l}47 \\
49 \\
47 \\
51\end{array}$ & $\begin{array}{l}28 \\
39 \\
28 \\
36\end{array}$ & $\begin{array}{l}38 \\
19 \\
28 \\
20\end{array}$ \\
\hline $\begin{array}{l}\beta B D 3 D-50 / 01 \\
\beta B D 3 D-70 / 01 \\
\beta B D 4 D-50 / 01 \\
\beta B D 4 D-70 / 01\end{array}$ & $\begin{array}{l}25 \\
13 \\
25 \\
13\end{array}$ & $\begin{array}{l}50 \\
58 \\
50 \\
58\end{array}$ & $\begin{array}{l}25 \\
29 \\
25 \\
29\end{array}$ & $\begin{array}{r}12 \\
4 \\
14 \\
4\end{array}$ & $\begin{array}{l}53 \\
53 \\
46 \\
49\end{array}$ & $\begin{array}{l}35 \\
43 \\
40 \\
44\end{array}$ & $\begin{array}{r}19 \\
8 \\
18 \\
6\end{array}$ \\
\hline $\begin{array}{l}\delta \text { VD3D-50/01 } \\
\delta \text { VD3D-70/01 } \\
\delta \text { VD4D-50/01 }\end{array}$ & $\begin{array}{l}25 \\
13 \\
25\end{array}$ & $\begin{array}{l}50 \\
58 \\
50\end{array}$ & $\begin{array}{l}25 \\
29 \\
25\end{array}$ & $\begin{array}{l}4 \\
2 \\
4\end{array}$ & $\begin{array}{l}48 \\
49 \\
48\end{array}$ & $\begin{array}{l}48 \\
49 \\
48\end{array}$ & $\begin{array}{l}0 \\
0 \\
0\end{array}$ \\
\hline $\begin{array}{l}\text { ЄCD3D-50/01 } \\
\epsilon \text { CD3D-70/01 } \\
\epsilon \text { CD4D-50/01 }\end{array}$ & $\begin{array}{l}25 \\
13 \\
25\end{array}$ & $\begin{array}{l}50 \\
58 \\
50\end{array}$ & $\begin{array}{l}25 \\
29 \\
25\end{array}$ & $\begin{array}{l}25 \\
10 \\
23\end{array}$ & $\begin{array}{l}38 \\
45 \\
39\end{array}$ & $\begin{array}{l}38 \\
45 \\
39\end{array}$ & $\begin{array}{l}0 \\
0 \\
0\end{array}$ \\
\hline
\end{tabular}

a Determined from ${ }^{1} \mathrm{H}$ NMR spectra in deuterated chloroform or trifluoroacetic acid; percentage of ether bonds (between $\delta=3.3$ and $3.6 \mathrm{ppm}$ ) with respect to ether and ester bonds (between $\delta=3.3$ and $4.8 \mathrm{ppm}$ ). ${ }^{b}$ Determined from ${ }^{1} \mathrm{H}$ NMR spectra in deuterated chloroform or trifluoroacetic acid. ${ }^{c} \beta \mathrm{B}=\beta$-butyrolactone; $\delta \mathrm{V}=\delta$-valerolactone; $\epsilon \mathrm{C}=\epsilon$-caprolactone. ${ }^{d} \mathrm{D} 3=1,3$-propanediol; $\mathrm{D} 4=1,4$ butanediol.

From the results of the carboxylic acid end-group determinations it appeared that the relative amount of the second type of carboxylic acid end groups increased from $30 \%$ at $60 \mathrm{~min}$ to $50 \%$ after $240 \mathrm{~min}$. No second equivalence point was found in the reaction products obtained at temperatures lower than $200^{\circ} \mathrm{C}$. This result is in agreement with the fact that interchange reactions usually occur only at high temperatures in the presence of a catalyst, e.g., TnBT.

Copolymer Synthesis Using Other Lactones. As shown before poly(ether ester)s can be obtained by using a two-stage melt process starting from PVL, alkanediols, and DMT. In order to investigate the influence of the type of lactone used on the products prepared by the twostage melt process, other lactones were also studied. As in the case of other cyclic monomers, the polymerizability of a lactone depends on parameters such as ring strain, basicity, and energy changes at the transition stage. Data concerning lactone polymerizability have been reported by Hall et al. ${ }^{39}$ According to Hall et al., due to thermodynamic reasons, $\gamma$-lactones as well as some substituted $\delta$-lactones cannot be (homo)polymerized.

The characteristics of the polymers obtained using various lactones (including PVL) are summarized in Table IV. It appeared from the ${ }^{1} \mathrm{H}$ NMR spectra that in the case of $\beta$-lactones, i.e., PVL and $\beta$-methyl- $\beta$-propiolactone ( $\beta$-butyrolactone; $\beta \mathrm{B}$ ), poly(ether ester)s were obtained. Comparing the data of the polymers prepared using $\beta$-lactones, it is clear that in the case of $\beta \mathrm{B}$ the amount of lactone units in the copolymer was lower than for polymers prepared from PVL. This is in accordance with the fact that $\beta \mathrm{B}$ is known to be less reactive with respect to ring opening by nucleophiles, due to steric hindrance of the methyl group present at the $\beta$-carbon atom in the initiation step. ${ }^{40}$

The fact that ether bonds were found in reaction products prepared from $\beta$-lactones, alkanediols, and DMT can be explained by the mechanism as indicated in Scheme V. As outlined before, the action of weak nucleophiles, e.g., diols, upon $\beta$-lactones results in the attack on the $\beta$-carbon atom followed by alkyl-oxygen bond scission. ${ }^{22,33-37}$ As shown in Scheme V, this attack gives rise to the formation of an ether bond and of a carboxylic acid 
end group ( $b$; Scheme V), which means that the end group is now a carboxylic acid end group instead of a hydroxyl end group. The presence of carboxylic acid end groups was confirmed by titration of products from the model reaction between PVL and BHBT (Figure 6B).

From Table IV it can be seen that by using six- and seven-membered lactones copolymers were obtained, in which no ether bonds were present. Although $\delta$-valerolactone $(\delta \mathrm{V})$ can be homopolymerized, the copolyesters from $\delta \mathrm{V}$ contained relatively small amounts of this lactone. Apart from reasons due to the low reactivity of this $\delta$-lactone under the conditions used, the small amounts of $\delta \mathrm{V}$ in the reaction products may also have been caused by depolymerization reactions of $\delta \mathrm{V}$ sequences, for these sequences may well be formed during the reactions. Saotome et al. reported that homopolymers of $\delta \mathrm{V}$ prepared by initiation with 1,2-ethanediol were easily depolymerized into the monomeric lactone at temperatures above 200 ${ }^{\circ} \mathrm{C} .{ }^{23}$ Considering the compositional data of the copolymers prepared from $\epsilon$-caprolactone $(\epsilon \mathrm{C})$, it should be noted that relatively large amounts of these units were present in the copolymers, as expected from data concerning lactone polymerizability. These results are in close agreement with those from the work of Tsai et al. on the synthesis of copolymers from $\epsilon \mathrm{C}, \mathrm{D} 4$, and terephthalic acid. ${ }^{12}$

In contrast with the copolymers prepared from $\beta$-lactones, the copolyesters prepared from the higher lactones contained a significant amount of lactone sequences, which can be explained as follows. As mentioned before, ring opening by hydroxyl groups occurs with acyl-oxygen bond scission in the case of $\delta$ - and $\epsilon$-lactones, ${ }^{18,21,23,24}$ resulting in the formation of an ester bond and in a hydroxyl end group ( $a$; Scheme V). Apart from the fact that during the initiation step different types of bonds were formed, the propagating species in the case of $\beta$-lactones were carboxylic acid end groups, whereas for higher membered lactones propagation proceeded via successive attacks of hydroxylend groups. Thus, lactone sequences are formed with higher lactones, whereas with PVL the formed carboxylic acid end groups did not give rise to further ring opening but were supposed to react with the present hydroxyl end groups. It was assumed that this mechanism occurs when $\beta$-lactones are concerned, resulting in the presence of isolated lactone units in the polymeric chains.

Apart from the above-mentioned results, it can be seen in Table IV that in the copolymers prepared from $\beta$-lactones the $\mathrm{D} n / \mathrm{DMT}$ ratio was larger than 1 . The deviation of the $\mathrm{D} n / \mathrm{DMT}$ ratio from 1 can be explained by the occurrence of reaction (3), for once reacted according to reaction (3) the $\mathrm{O}\left(\mathrm{CH}_{2}\right)_{n} \mathrm{O}$ groups remain in the polymer molecules during the polycondensation step. The copolymers obtained from $\delta$ - and $\epsilon$-lactones, on the other hand, showed always a Dn/DMT ratio equal to 1 . Evidently, the synthesis of copolymers from the higher-membered lactones resembles the preparation of poly(alkylene terephthalate)s; i.e., during polycondensation diol is removed from the reaction mixture, thus resulting in a $\mathrm{D} n / \mathrm{DMT}$ ratio of 1 .

\section{Conclusion}

Copolymers of PVL, alkanediols, and DMT were prepared via a two-stage melt process. From the NMR spectra of the reaction products, it appeared that these materials contained a significant amount of ether bonds. The structure of the products was elucidated by a detailed NMR study of the copolymers prepared from PVL, D3, and DMT. With the propylene unit as the central unit six structures were found present: apart from three completely esterified structures, one two-sided etherified structure and two mixed structures could be identified. The copolymers prepared could be completely described by these six structures together with two structures consisting of a PVL unit next to a terephthalate unit and next to a PVL unit. Using the NMR assignments, it appeared that the copolymers consisted mainly of two completely esterified structures, i.e., terephthalate-propylene-terephthalate and terephthalate-propylene-PVL, and one mixed structure, i.e., terephthalate-propylenePVL, in which the propylene and the PVL unit are linked through an ether bond. Furthermore, the copolymers contained no or only a few mol \% of PVL sequences.

The reactions responsible for the formation of the poly(ether ester)s were studied in detail using a model system consisting of BHBT and PVL. It appeared that at 200 ${ }^{\circ} \mathrm{C}$, i.e., the temperature applied in the first stage of the melt process, the conversion of PVL was already complete after $15 \mathrm{~min}$ of reaction. From NMR spectra and endgroup determinations it could be concluded that initiation occurred by attack on the $\beta$-carbon atom followed by alkyloxygen bond scission and that, instead of propagation through successive attacks on PVL, the formed carboxylic acid end groups reacted with hydroxyl groups of BHBT. As a result, ether bonds were formed and PVL units were only found present isolated in the polymeric chains. Although poly(ether ester)s were also obtained from the melt process using no catalyst or SnOct as a catalyst, it appeared that the reaction products contained several mol $\%$ of PVL sequences.

Ether bonds and isolated lactone units were also present in copolymers prepared from $\beta \mathrm{B}, \mathrm{DMT}$, and alkanediols, indicating that the mechanism proposed could generally be applied when using $\beta$-lactones. The use of six- and seven-membered lactones resulted in the formation of copolyesters containing significant amounts of lactone sequences, whereas no ether bonds were present. These copolymers showed a Dn/DMT ratio of 1 , which has also been found for poly(alkylene terephthalate)s.

Acknowledgment. The authors thank Mr. J. Beulen for the NMR analysis and Mr. L. W. Maesen for carrying out the titrations (both from DSM Research).

\section{References and Notes}

(1) Toyobo Co., Ltd. Japan Kokai 73 00,991, 1973; Imanaka, H.; Sumoto, M. Chem. Abstr. 1973, 78, 137334s.

(2) Toyobo Co., Ltd. Japan 73 04,116, 1973; Sumoto, M.; Miwa, S.; Imanaka, H. Chem. Abstr. 1974, 80, 16127j.

(3) Toyo Spinning Co., Ltd. Japan 73 04,115, 1973; Chem. Abstr. $1974,80,16283 \mathrm{~g}$.

(4) Toyobo Co., Ltd. Eur. Pat. Appl. EP 208,131, 1985; Kobayashi, T.; Kitagawa, H.; Kaneshige, N.; Makumura, O. Chem. Abstr. $1987,106,121165 y$.

(5) Kanegafuchi Chemical Industry Co., Ltd. Japan Kokai Tokkyo Koho JP 02 252,729, 1989; Yoshida, T.; Ohara, H.; Noda, T. Chem. Abstr. 1991, 114, 43818n.

(6) Luo, X.; Du, D.; Ma, D. Zhongguo Kexue Jishu Daxue Xuebao 1986, 16, 280; Chem. Abstr. 1987, 106, 85342t.

(7) Hu, S.; Xu, M.; Zhang, X.; Ma, D.; Luo, X. Chin. J. Polym. Sci. 1988, 6, 64; Chem. Abstr. 1988, 109, 129969w.

(8) Luo, X.; Ma, D. Gaofenzi Xuebao 1989, 676; Chem. Abstr. 1990, $113,133183 \mathrm{k}$.

(9) Luo, X.; Ma, D.; Jiang, W. Zhongguo Kexue Jishu Daxue Xuebao 1990, 20, 220; Chem. Abstr. 1991, 115, 9729v.

(10) Asahi Kasei Kabyshiki Kaisha. GB 1076877, 1967.

(11) Imperial Chemical Industries, Ltd. Fr. 1,523,057, 1968; Chem. Abstr. 1969, 70, 116323g.

(12) Tsai, H.; Kuo, W.; Chen, M.; Chang, N.; Chen, S.; Chang, S. J. Appl. Polym. Sci. 1990, 39, 233.

(13) Tijsma, E. J.; van der Does, L.; Bantjes, A.; Vulic, I. Makromol. Chem. 1993, 194, 305. 
(14) Tijsma, E. J.; van der Does, L.; Bantjes, A.; Vulić, I.; Werumeus Buning, G. H. Makromol. Chem., in press.

(15) Tijsma, E. J.; van der Does, L.; Bantjes, A.; Vulić, I.; Werumeus Buning, G. H., in preparation.

(16) Buyle Padias, A.; Hall, H. K., Jr. J. Polym. Sci., Polym. Chem. Ed. 1981, 19, 1021.

(17) Dee, L. A.; Biggers, B. L.; Fiske, M. E. Anal. Chem. 1980, 52, 572.

(18) Schindler, A.; Hibionada, Y.M.; Pitt, C.G.J.Polym. Sci., Polym. Chem. Ed. 1982, 20, 319

(19) Bremser, W.; Franke, B.; Wagner, H. Chemical Shift Ranges in Carbon-13 NMR Spectroscopy; Verlag-Chemie: Weinheim, FRG, 1982

(20) Jerôme, R.; Teyssié, P. In Anionic Ring-Opening Polymerization: Lactones. Comprehensive Polymer Science; Allen, G.; Bevington, J. C., Eds.; Pergamon Press: Oxford, 1989; Vol. 3, p 501.

(21) Hofman, A.;Slomkowski, S.; Penczek, S.Makromol. Chem. 1987, $188,2027$.

(22) Jedlinski, Z.; Kowalczuk, M. Macromolecules 1989, 22, 3242.

(23) Saotome, K.; Kodaira, Y. Makromol. Chem. 1965, 82, 41.

(24) Bassi, M. B.; Buyle Padias, A.; Hall, H. K., Jr. Polym. Bull. $1990,24,227$.

(25) Hofman, A.; Slomkowski, S.;Penczek, S.Makromol.Chem. 1984, $185,91$.
(26) Yamashita, Y.; Tsuda, T.; Ishida, H.; Uchikawa, A.; Kuryama, Y. Makromol. Chem. 1968, 113, 139.

(27) Dale, J.; Schwartz, J.-E. Acta Chem. Scand. 1986, B40, 559.

(28) Kricheldorf, H. R.; Scharnagl, N.J.Macromol. Sci., Chem. 1989, A26, 951.

(29) Jedlinski, Z.; Kowalczuk, M.; Kurcok, P. Macromolecules 1991, 24, 1218.

(30) Kurcok, P.; Kowalczuk, M.; Hennek, K.; Jedlinski, Z. Macromolecules 1992, 25, 2017.

(31) Jedlinski, Z. Makromol. Chem., Makromol. Symp. 1992, 60, 235.

(32) Etienne, Y.; Soulas, R. J. Polym. Sci., Part C 1964, 4, 1061.

(33) Cornibert, J.; Marchessault, R. H.; Allegrezza, A. E., Jr.; Lenz, R. W. Macromolecules 1973, 6, 676 .

(34) Hall, H. K., Jr. Macromolecules 1969, 2, 488.

(35) Wilson, D. R.; Beaman, R. G. J. Polym. Sci., Polym. Chem. Ed. $1970,8,2161$.

(36) Jaacks, V.; Mathes, N. Makromol. Chem. 1970, 131, 295.

(37) Bigdelli, E.; Lenz, R. W. Macromolecules 1978, 11, 493.

(38) Yamashita, Y.; Hane, T. J. Polym. Sci., Polym. Chem. Ed. 1973, $11,425$.

(39) Hall, H. K., Jr.; Schneider, H. K. J. Am. Chem. Soc. 1958, 80, 6409.

(40) Iida, M.; Araki, T.; Teranishi, K.; Tani, H. Macromolecules 1977, 10, 275. 